\title{
Da reforma à revolução: a contribuição da reforma protestante à teoria da soberania popular
}

From reformation to revolution: the xvicentury's reformation contribution to the theory of people's sovereignity

\section{Marcelo Campos Galuppo ${ }^{1}$}

Resumo: O desenvolvimento da doutrina desenvolvida pelos Reformadores do século XVI é importante para compreendermos o fundamento do problema da legitimidade do poder civil, de seus limites e do controle que a vontade popular exerce sobre ele. Partindo de uma posição de total submissão em Lutero, até se chegar a uma posição de incentivo à desobediência de leis injustas em John Knox, em um curto espaço de trinta e cinco anos, o fundamento teológico do poder foi reelaborado para comportar as transformações profundas por que passava a sociedade, com a passagem da soberania monárquica para a soberania popular e com a emergência de limites racionais à vontade do governante.

1 Doutor em Filosofia do Direito pela UFMG (1998). Professor da Faculdade de Direito da Universidade Federal de Minas Gerais. Professor da Faculdade Mineira de Direito da Pontifícia Universidade Católica de Minas Gerais. 
Palavras-chave: Cristianismo e Direito; Desobediência Civil; Estado de Direito; Filosofia do Direito - História

Abstract: The development of the XVI Century`s Reformation Doctrine is very important in order to understand the grounding of the legitimacy of Civil Power, of its limits and of the control that popular will exercise on it. Departing from Lutheran position, of total submission to the Sovereign, to the incentive to civil disobedience by John Knox (in just thirty five years), the theological foundation of Civil Power was completely reëlaborated to accommodate the deep transformations in society, namely the changing from monarchic sovereignty to popular sovereignty and the rising of rational limits to the ruler's will.

Keywords: Law and Christianity; Civil Disobedience; Rule of Law; Philosophy of Law - History

\section{Da reforma à revolução: $O$ dever de obediência às autoridades}

Os textos do apóstolo Paulo sempre foram motivo de grande divergência entre cristãos. Textos sobre a submissão das mulheres aos homens ${ }^{2}$ e sobre a pecaminosidade da homossexualidade ${ }^{3}$ sempre intrigaram, incomodaram e opuseram fiéis em grupos diferentes. $\mathrm{O}$ mesmo ocorre com a questão da autoridade civil. Devem os cristãos submeter-se ao poder civil, qualquer que seja ele, e quaisquer que forem suas ordens, ou os cristãos, por filiarem-se não apenas ao reino "deste mundo" ${ }^{4}$, mas também ao reino instaurado por Jesus Cristo, devem escolher a que normas e a que governantes obedecer?

2 Epístola de Paulo aos Efésios, capítulo 5, versículos 22 e seguintes.

3 Primeira Epístola de Paulo aos Coríntios, capítulo 5, versículos 9 e 10.

4 Evangelho de João, capítulo 18, versículo 36. 
No caso da autoridade civil, a crux interpretorum é apresentada por Paulo no capítulo 13 da Epístola aos Romanos:

Seja todo homem submisso às autoridades que exercem o poder, pois não há autoridade a não ser por Deus e as que existem são estabelecidas por ele. Assim, aquele que se opõe à autoridade se revolta contra a ordem querida por Deus, e os rebeldes atrairão a condenação sobre si mesmos. Com efeito, os magistrados não são temíveis quando se faz o bem, mas quando se faz o mal. Queres não ter de temer a autoridade? Faze o bem e receberás o seus elogios, pois ela está a serviço de Deus para te incitar ao bem. Mas se fazes o mal, então teme. Pois não é em vão que ela traz a espada: castigando, está a serviço de Deus para manifestar a sua cólera para com o malfeitor. Por isso é necessário submeter-se, não por temor da cólera, mas também por motivo de consciência. Este é também o motivo pelo qual pagais impostos: os que os recebem são encarregados por Deus de se dedicarem a este ofício. Dai a cada um o que lhe é devido: o imposto, as taxas, o temor, o respeito, a cada um o que lhe deveis ${ }^{5}$.

Essa orientação não é exclusivamente paulina, havendo um equivalente petrino em sua primeira epístola: "Sede submissos a qualquer instituição humana por causa do Senhor: quer ao rei, porque é o soberano, quer aos governadores, delegados por ele para punir os malfeitores e louvar as pessoas de bem ${ }^{6 \prime \prime}$. Não se trata, portando, de uma idiossincrasia de Paulo, ou de um viés autoritário e elitista deste apóstolo, mas de uma orientação consistente da doutrina apostólica em geral. Também não se pode partir de um pressuposto exclusivamente historicista para

5 PAULO (Apóstolo). Epístola aos Romanos. In BÍBLIA SAGRADA. Tradução Ecumênica da Bíblia. São Paulo: Loyola, 1994. P. 2195 (capítulo 13, versículos 1 a 07). Todas as citações das escrituras serão feitas a partir dessa tradução, empreendimento conjunto de Católicos Romanos, Protestantes e Judeus.

6 PEDRO (Apóstolo). Primeira Epístola de Pedro. In BÍBLIA SAGRADA. Tradução Ecumênica da Bíblia. São Paulo: Loyola, 1994. P. 2386 (capítulo 2, versículos 13 e 14) 
se afirmar que o ensino de Paulo ou de Pedro seria o ensino de homens históricos para homens históricos, que não se aplicariam fora do contexto em que ele foi produzido, pois toda a possibilidade de um conhecimento teológico reside no reconhecimento de que o texto bíblico é inspirado (por Deus) e, portanto, universalmente válido ${ }^{7}$.

O problema da autoridade civil foi enfrentado pelos reformadores ao longo do século XVI: entre 1517 e 1588, muito se escreveu sobre a questão da obediência aos magistrados, e a evolução do pensamento desses pensadores permite-nos compreender sua contribuição para a discussão acerca da titularidade e limitação da soberania.

\subsection{Lutero}

Um dos primeiros textos sobre o tema foi escrito por Lutero, em 1523: Da autoridade secular: até que ponto se lhe deve obediência. Quando publicou o texto, Lutero já fora excomungado pela Bula Decet Romanum Pontificem (de 1521) e a dieta de Worms já levara à separação formal e definitiva entre a Igreja Católica e a Igreja Luterana ${ }^{8}$ A essa altura, os anabatistas já empreenderam sua reforma radical, Thomas Müntzer já escrevera inúmeros tratados ${ }^{9}$ e a Guerra dos Camponeses na Suábia ${ }^{10}$ já se prenunciava.

7 BARTH, Karl. The epistle to the Romans. Oxford: Oxford University, 1968. P. 1.

8 LINDBERG, Carter. História da Reforma. Rio de Janeiro: Thomas Nelson, 2017.

9 Por uma questão metodológica, a Reforma de Müntzer foi deixada de lado neste trabalho, já que não obteve o alcance e nem deixou o legado (em termos de constituição de Igrejas mundiais que perdurassem até o século XXI) das reformas Luterana e Calvinista.

10 A guerra da Suábia levaria Lutero a escrever o tratado Contra as hordas salteadoras e assassinas de camponeses, em 1525, no qual recomendaria à nobreza, baseada na autoridade que as escrituras lhe conferiam, que "apunhal[asse], 
É no Da autoridade secular que uma das doutrinas fundamentais do luteranismo se apresenta pela primeira vez e do modo mais perfeito possível: a doutrina dos dois reinos. Para Lutero, o cristão vive sob o governo de dois reinos, sendo preciso obedecer a ambos. O primeiro reino seria o reino espiritual, a que pertencem apenas os cristãos e que governaria as almas. O segundo reino, o temporal, governaria os corpos e os bens, e a ele pertenceriam todos os súditos de um Estado ${ }^{11}$. A ordem, promovida pela atribuição de funções diferentes a cada um dos reinos, corrompe-se quando os príncipes arvoram-se "a exercer domínio espiritual sobre as almas, enquanto os outros [os religiosos] querem governar secularmente"12. O texto apresenta portanto uma crítica à pretensão do Kaiser de impor uma fé aos luteranos e, ao mesmo tempo, uma crítica à pretensão da Igreja Católica de julgar e impor penas físicas aos alemães.

Para que o argumento do texto de Lutero funcione, ele precisa basear-se no reconhecimento da legitimidade da autoridade civil, e portanto no dever de os súditos obedecerem-na com seus corpos e seus bens. Por isso Lutero afirma que "o cristão se submete de bom grado ao regime da espada: paga impostos, honra a autoridade, auxilia e faz tudo o que pode e que é útil para a autoridade, a fim de que sejam preservados seu poder, honra e temor" ${ }^{\prime 13}$. Esse dever

bat[esse], estrangul[asse] quem puder" dentre os revoltosos (LUTERO, Martinho. Contra as hordas salteadoras e assassinas dos camponeses. In: BONI, Luis Alberto de (org.). Escritos seletos de Martinho Lutero, Tomás Müntzer e João Calvino . Petrópolis: Vozes, 2000. P. 172).

11 LUTERO, Martinho. Da autoridade secular: Até que ponto se lhe deve obediência. In: BONI, Luis Alberto de (org.). Escritos seletos de Martinho Lutero, Tomás Müntzer e João Calvino . Petrópolis: Vozes, 2000. P. 89

12 LUTERO, Martinho. Da autoridade secular: Até que ponto se lhe deve obediência. In: BONI, Luis Alberto de (org.). Escritos seletos de Martinho Lutero, Tomás Müntzer e João Calvino . Petrópolis: Vozes, 2000. P. 107.

13 LUTERO, Martinho. Da autoridade secular: Até que ponto se lhe deve 
de obediência vai além do reconhecimento da legitimidade do poder secular, e exige do cristão que ele colabore com o governante de maneira ativa e positiva. A obediência cristã não é mera resignação, mas essencialmente ágape, serviço. Por isso Lutero ordena a todos cristãos: "Ao veres que há falta de carrasco, agente policial, juiz, senhor ou príncipe e te julgares apto, deverias oferecer e candidatar-se para que, de forma alguma, a autoridade tão necessária seja desprezada, enfraquecida ou desapareça"14.

A questão mais controversa abordada por Lutero no tratado é como devemos comportar-nos diante de ordens flagrantemente injustas emitidas por uma autoridade civil que se converteu em tirano. Para responde-la, Lutero invoca o caso da cidade de Meissen, em que os governantes católicos exigiram que os habitantes entregassem à autoridade os exemplares do Novo Testamento por ele traduzido e publicado um ano antes. A resposta de Lutero para esse problema é a seguinte:

Seus súditos devem proceder da seguinte forma: não devem entregar nem uma folhinha, nenhuma letra sequer, sob pena de perderem a salvação eterna (...). Por outro lado, devem tolerar que se ordene revistar-lhes as casas e levar livros e bens pela força. Ao mal não se deve resistir, mas tolerá-lo. No entanto, não se deve aprova-lo nem colaborar com ele ou seguir e obedecer-lhe sequer com um passo ou com um dedo ${ }^{15}$.

O dever de obediência do súdito incide sobre seu corpo, não sobre sua alma. Portanto, é um direito do súdito

obediência. In: BONI, Luis Alberto de (org.). Escritos seletos de Martinho Lutero, Tomás Müntzer e João Calvino . Petrópolis: Vozes, 2000. P. 92.

14 LUTERO, Martinho. Da autoridade secular: Até que ponto se lhe deve obediência. In: BONI, Luis Alberto de (org.). Escritos seletos de Martinho Lutero, Tomás Müntzer e João Calvino . Petrópolis: Vozes, 2000. P. 94.

15 LUTERO, Martinho. Da autoridade secular: Até que ponto se lhe deve obediência. In: BONI, Luis Alberto de (org.). Escritos seletos de Martinho Lutero, Tomás Müntzer e João Calvino . Petrópolis: Vozes, 2000. P. 109. 
resistir a toda ordem do governante que coloque em risco sua salvação eterna. Essa resistência significa, porém, apenas o descumprimento da lei, com a consciência de que, ao fazê-lo, o súdito a infringe e portanto passa a ser um malfeitor aos olhos da autoridade e, consequentemente, deve suportar, sobre seus bens e sobre seu corpo, as penas que o tirano lhe aplicar. Podemos, pois, eximirmo-nos legitimamente de cumprir a ordem exarada pelo tirano, mas não de suportar sua espada. Posso descumprir algumas leis injustas, cujo cumprimento implicaria minha danação eterna, desde que esteja disposto a suportar as consequências no reino temporal desse descumprimento. Pois o governo do corpo pertence ao governante, e o cristão pode opor-se ao tirano em sua alma, mas não com seu corpo. Em hipótese alguma o cristão está autorizado a defender-se, seja de um malfeitor, seja de um tirano: "nenhum cristão deve tomar e invocar a espada para si e sua causa"16.

\subsection{Calvino}

Uma primeira leitura das Institutas nos leva a pensarmos que a reforma calvinista tomou o mesmo rumo da reforma luterana na questão do dever de obediência à autoridade civil. Na redação latina definitiva das Institutas, de $15599^{17}$, Calvino escreve que é um dever do cristão submeter-se ao governo civil.

A visão de Calvino sobre o governo civil é mais institucional e constitutiva que a visão de Lutero. Lutero

16 LUTERO, Martinho. Da autoridade secular: Até que ponto se lhe deve obediência. In: BONI, Luis Alberto de (org.). Escritos seletos de Martinho Lutero, Tomás Müntzer e João Calvino . Petrópolis: Vozes, 2000. P. 101.

17 Calvino publicou três edições das Institutas, com reformulações sucessivas. A primeira, de 1536, em Latim, quando ainda residia na França, a segunda, em francês, de 1541, e a Terceira, definitiva, em latim, aqui consultada, de 1559. 
acreditava que o governo civil e o poder da espada que lhe é inerente só existiriam por causa do pecado e da maldade, como um mecanismo para combate-los: Deus submeteu a todos "à espada, a fim de que, ainda que o queiram, não possam praticar sua maldade e, caso a [pratiquem], não o possam fazer sem temor e em paz e felicidade" 18 . Para Calvino, diferentemente de Lutero, o Estado existiria não apenas para combater o mal, mas também para instituir providencialmente a ordem necessária ao bom funcionamento de qualquer sociedade humana:

Reis e magistrados exercem sobre a terra a sua autoridade, não por conta da perversidade humana, mas por provida e santa ordenação de Deus, a quem pareceu bem conduzir assim o governo dos homens. Pois é ele que se faz presente e preside a formulação das leis e a reta administração da justiça. (...) Toda autoridade é uma ordenação divina e (...) não há poder algum que não tenha sido estabelecido por Deus (Rm 13. 1,2). Ao contrário, os príncipes são ministros de Deus para honrar àqueles que fazem o bem, e para castigar aos que agem $\mathrm{mal}^{19}$.

Enquanto Lutero acredita que um (bom) cristão lesado por um particular (como um comerciante ou um ladrão) deveria eximir-se de recorrer ao Estado para ser recompensado, pois "quem ama a seus inimigos e é perfeito, abandona a lei, não tendo necessidade dela para pedir olho por olho" ${ }^{20}$, Calvino acredita que não só o cristão não peca ao recorrer ao magistrado para se recompor de algum agravo, mas exerce seu dever como cristão ao fazê-lo, pois

18 LUTERO, Martinho. Da autoridade secular: Até que ponto se lhe deve obediência. In: BONI, Luis Alberto de (org.). Escritos seletos de Martinho Lutero, Tomás Müntzer e João Calvino . Petrópolis: Vozes, 2000. P. 89.

19 CALVINO, João. A Instituição da religião cristã. São Paulo: UNESP, 2009. Tomo II (livros III e IV). P. 878. (item 4 do cap. XX do livro IV).

20 LUTERO, Martinho. Da autoridade secular: Até que ponto se lhe deve obediência. In: BONI, Luis Alberto de (org.). Escritos seletos de Martinho Lutero, Tomás Müntzer e João Calvino . Petrópolis: Vozes, 2000. P. 100. 
Dado que Paulo declara abertamente que o magistrado é ministro de Deus para o bem (Rm 13.4), devemos concluir que é a vontade de Deus que a sua autoridade e auxílio nos defendam e tutelem contra a maldade e a injustiça dos maus, de modo que possamos viver em paz sob a sua proteção. Em vão Deus ter-nos-ia constituído juízes para nos tutelar caso não fosse lícito usar desse benefício; daí se segue, evidentemente, que podemos recorrer ao magistrado sem cometer pecado ${ }^{21}$.

Essa disposição diante da autoridade civil que a reconhece como ministro de Deus leva Calvino a aparentemente rechaçar nas Institutas qualquer direito de o súdito revoltar-se, insurgir-se ou mesmo apenas resistir ao poder secular:

se aqueles que, por vontade de Deus, vivem sob príncipes, dos quais são súditos naturais, transferem o poder a si próprios mediante a revolta, digo que semelhante tentativa deve ser considerada não somente absurdo, mas deplorável e danosa aventura $^{22}$.

A autoridade, tal como instituída na Epístola de Romanos, é absoluta, e por isso nem contra o governante tirânico o súdito tem o direito de rebelar-se:

A palavra de Deus (...) nos fará obedecer, não somente aos príncipes que cumprem o seu dever e mandato, mas a todos os que ocupam uma posição eminente, embora não façam o que a sua posição exige. Porque o Senhor declara que os magistrados foram constituídos para a conservação do gênero humano, e, embora lhes imponha limites definidos, declara no entanto que, sendo quem forem, receberam o governo diretamente Dele. (...) Aos súditos compete que tributem à má autoridade a mesma reverência que rendem a um bom rei $^{23}$.

21 CALVINO, João. A Instituição da religião cristã. São Paulo: UNESP, 2009. Tomo II (livros III e IV). P. 891. (item 17 do cap. XX do livro IV).

22 CALVINO, João. A Instituição da religião cristã. São Paulo: UNESP, 2009. Tomo II (livros III e IV). P. 882. (item 8 do cap. XX do livro IV).

23 CALVINO, João. A Instituição da religião cristã. São Paulo: UNESP, 2009. Tomo 
No entanto, e aqui começa a evolução do pensamento reformado, Calvino já estabelecia uma exceção a essa regra: "Se as autoridades ordenam algo contra o mandamento de Deus, devemos desconsiderá-la completamente, seja quem for o mandante" 24 . Esse seu entendimento irá se aprofundar progressivamente e, ao redigir no final de sua vida o comentário ao versículo 29 do capítulo $5^{\circ}$ do livro dos Atos dos Apóstolos ${ }^{25}$, Calvino afirmou que

Deus estabelece homens com poder sobre nós de tal forma que ele ainda preserve sua própria autoridade segura e íntegra. Portanto, devemos obedecer aos governantes apenas na medida em que não se quebrem os comandos de Deus. (...) Se um magistrado realiza sua tarefa como deve, um homem diria em vão que tal magistrado é contrário a Deus. (...) Mas na medida em que os governantes nos afastam da obediência a Deus, porque desafiam a Deus com coragem sacrílega, seu orgulho deve ser abatido, para que Deus (se imponha) sobre toda autoridade ${ }^{26}$.

A partir de então, Calvino começa a expressar timidamente a ideia de que reservas materiais ao poder do governantes podem limitar e excepcionar seu poder formal. De certa forma, como veremos mais abaixo, o fato de Calvino ter escrito a primeira edição das Institutas ainda na França e de os comentários serem obra do final de sua vida, já em Genebra, é decisivo para essa mudança de entendimento, refletindo suas experiências políticas passadas.

A grande novidade das Institutas em relação a Lutero, no entanto, é o desenvolvimento da doutrina dos magistrados

II (livros III e IV). P. 897. (item 25 do cap. XX do livro IV).

24 CALVINO, João. A Instituição da religião cristã. São Paulo: UNESP, 2009. Tomo II (livros III e IV). P. 902. (item 32 do cap. XX do livro IV).

25 "É preciso obedecer antes a Deus do que aos homens". LUCAS (São). Atos dos Apóstolos. In BÍBLIA SAGRADA. Tradução Ecumênica da Bíblia. São Paulo: Loyola, 1994. P. 2112. (capítulo 5, versículo 29).

26 CALVIN, John. The Commentaries of M. John Calvin upon the Actes of the Apostles. In: Calvin's Commentaries. Grand Rapids: Baker, 2005. Vol XVIII [parte II], p. 214-5. 
menores. Calvino afirma que

embora a punição de uma autoridade desordenada seja ato de vingança de Deus, não devemos concluir que ela nos tenha sido confiada e seja lícito exercê-la. Refiro-me sempre a pessoas particulares. Porque, se em nossos dias existirem magistrados instituídos para a tutela do povo e para conter a excessiva licença e a cobiça dos soberanos (...), a estas pessoas, que estão investidas de autoridade, não posso de modo algum proibir, segundo as exigências de seu ofício, que façam oposição e resistam à excessiva licença dos reis, pois, deixando de fazê-lo, trairão ao dever de proteger a liberdade do povo $^{27}$.

De modo algum o povo possui o poder de punir, destituir ou mesmo opor-se ao governante, pois apenas os magistrados detêm poder civil necessário para fazê-lo. Mas a Epístola de Romanos diz que todos os magistrados, e não apenas os soberanos, detêm poder civil, e ainda que o povo não possa opor-se ao governante, outros magistrados podem fazê-lo. Essa doutrina, que passou a ser conhecida como a doutrina dos magistrados menores (ou lesser magistrates), exercerá um papel decisivo no curso da Reforma.

\subsection{A Confissão de Magdeburg}

Ainda que Calvino tenha exposto a ideia antes de os luteranos fazerem-no, é a partir dos discípulos de Lutero que a doutrina dos lesser magistrates se desenvolverá e se tornará conhecida.

Em 1521, Lutero fora condenado no Édito de Worms, que decorreu de sua recusa de rejeitar seus escritos e ensinos na Dieta de Worms. Em 1530, Lutero apresenta uma defesa consolidada de suas convicções na Dieta de Augsburg e alerta aos príncipes luteranos sobre a possibilidade de uma reação militar por parte do Kaiser Carlos V. Isso levou à

27 CALVINO, João. A Instituição da religião cristã. São Paulo: UNESP, 2009. Tomo II (livros III e IV). P. 901. (item 31 do cap. XX do livro IV). 
constituição da Liga de Esmalcalda,

formada pelos Príncipe Filipe de Hesse e pelo Príncipe João Frederico I da Saxônia, os dois governantes protestantes mais poderosos naquele momento. A liga era uma aliança religiosa de defesa, na qual os membros comprometiam-se a defenderem-se reciprocamente, caso seus territórios fossem atacados por Carlos $\mathrm{V}^{28}$.

Em 1546, Carlos V começa sua ofensiva militar contra os Príncipes Protestantes, e em 24 de abril do ano seguinte, na batalha de Muhlberg, ele captura o Príncipe Filipe de Hesse e o Príncipe João Frederico da Saxônia ${ }^{29}$, os principais líderes luteranos entre a nobreza. Fortalecido, o Kaiser publica em 15 de maio de 1548 o Interim de Augsburg, documento imperial que restaurou a fé católica (exceto com relação ao casamento do clero e à eucaristia com dois elementos, tal como preconizara Lutero) $)^{30}$.

A principal resistência à ofensiva militar de Carlos $\mathrm{V}$ e ao Interim de Augsburg foi da cidade de Magdeburg, teologicamente liderada por um pastor luterano chamado Nicholas von Amsdorff. Juntamente com outros oito colegas pastores, Amsdorff redigiu no dia 13 de abril de 1550 a Confissão e defesa dos pastores e outros ministros da Igreja de Magdeburg ${ }^{31}$. Em outubro de 1550, Carlos V começava o cerco

28 GRANT, George. Historical Setting. In: AMSDORFF, Nicholas von. The Magdeburg Confession. Trad. Matthew Colvin. North Charleston: Create Space, 2012. P. XXX.

29 GRANT, George. Historical Setting. In: AMSDORFF, Nicholas von. The Magdeburg Confession. Trad. Matthew Colvin. North Charleston: Create Space, 2012. P. XXXI.

30 GRANT, George. Historical Setting. In: AMSDORFF, Nicholas von. The Magdeburg Confession. Trad. Matthew Colvin. North Charleston: Create Space, 2012. P. XXXI.

31 GRANT, George. Historical Setting. In: AMSDORFF, Nicholas von. The Magdeburg Confession. Trad. Matthew Colvin. North Charleston: Create Space, 2012. P. XXXII. 
de Magdeburg. Quando o cerco terminou, com o insucesso do Kaiser, Maurício da Saxônia atacou Carlos V e o fez retirar-se para a Itália. O imperador se viu obrigado a assinar a Paz de Passau, em agosto de 1552, garantindo liberdade religiosa aos reformadores. Essa decisão foi estabilizada na Paz de Augsburg, em 25 de setembro de $1555^{32}$, que fixou a doutrina cuius regio, eius religio (de quem for a região, dele será a religião, ou seja, o povo teria a religião de seu governante). Finalmente os luteranos haviam vencido ${ }^{33}$ : Cada príncipe seria o responsável por determinar a religião dos moradores de seu principado.

No texto da confissão, Amsdorff retomou os argumentos sobre a separação dos dois reinos apresentados por Lutero em Da autoridade Secular, afirmando, no entanto, que Carlos V estaria "excedendo os limites de seu domínio e estendendo-o ao domínio de Cristo" ${ }^{34}$. Mas a Confissão não se limita a afirmar uma violação da fronteira entre os dois reinos. Os fundamentos apresentados por Amsdorff e seus colegas na Confissão indicam uma radicalização das ideias de que o poder do governante nasce de alguma forma limitado. Como diz a confissão, "quando os magistrados (...) levam seus poderes além da verdadeira piedade e correção, a obediência não lhes é devida, segundo a palavra de Deus" ${ }^{\prime 35}$.

32 GRANT, George. Historical Postscript. In: AMSDORFF, Nicholas von. The Magdeburg Confession. Trad. Matthew Colvin. North Charleston: Create Space, 2012. P. 92.

33 Uma vitória provisória, que levaria à Guerra dos Trinta Anos, cujo fim traria, conjuntamente, o fim da doutrina cujus regio, ejus religio, radicalizando ainda mais a liberdade religiosa instaurada pela Reforma Protestante: A partir da Paz de Vestfália (1648), a nem o imperador, nem mais os príncipes, poderiam determinar a religião de seus súditos.

34 AMSDORFF, Nicholas von et alii. The Magdeburg Confession. Trad. Mathew Colvin. North Charleston: Create Space, 2012. P. 53.

35 AMSDORFF, Nicholas von et alii. The Magdeburg Confession. Trad. Mathew Colvin. North Charleston: Create Space, 2012. P. 42. 
Ainda que os cidadãos não possam opor-se ao tirano, os "magistrados piedosos não apenas são aptos, mas inclusive possuem a obrigação de resistir-lhes enquanto forem capazes de fazê-lo" ${ }^{\prime 36}$. Os magistrados menores, como por exemplo os príncipes eleitores, podem opor-se ao magistrado soberano (o Kaiser) porque são também magistrados, e a Epístola de Paulo aos Romanos não distingue entre eles ao dizer que compete aos magistrados administrar a justiça e zelar pelo bem estar de seus súditos. Essa mudança de entendimento foi decisiva para o próprio sucesso da Reforma Protestante:

Sabe-se que a Confissão de Magdeburg e a posição tomada por esses homens impactaram John Knox, que conduziu a reforma na Escócia, e Theodore Beza, que foi o sucessor de Calvino. Ambos iriam desenvolver a doutrina dos magistrados menores sobre o que foi escrito [na Confissão]. Se não fosse pela ação dos habitantes de Magdeburg, toda a Reforma poderia ter sido apenas uma centelha no radar da história ${ }^{37}$.

\subsection{Theodore de Beza}

Com a morte de Calvino, em 1564, seu discípulo Theodore de Beza assume a liderança do governo da Igreja Reformada de Genebra. Após o massacre da Noite de São Bartolomeu na França, em 24 de agosto de 1572, Beza escreve aquele que é provavelmente o mais importante tratado teológico-político do protestantismo do século XVI: o Direito dos Magistrados sobre seus súditos, de 1574. Aqui, a teologia política reformada se tornará mais teoria política do que teologia ${ }^{38}$, e se afastará decisivamente da oposição

36 AMSDORFF, Nicholas von et alii. The Magdeburg Confession. Trad. Mathew Colvin. North Charleston: Create Space, 2012. P. 55.

37 GRANT, George. Historical Postscript. In: AMSDORFF, Nicholas von. The Magdeburg Confession. Trad. Matthew Colvin. North Charleston: CreateSpace, 2012. P. 91.

38 Diferentemente de seus predecessores, muitos de seus argumentos são 
de Lutero e da timidez de Calvino sobre o tema. Como disse Julian Franklin, Beza desenvolve aquilo que se encontrava, na melhor das hipóteses, apenas implícito naqueles autores, mas que aí já se prenunciava:

Lutero e Calvino geralmente opõem-se a qualquer coisa que não fosse uma resistência passiva no espírito da Igreja Primitiva. No entanto, uma contracorrente pode ser percebida no pensamento deles, que sempre esteve latente na Reforma e que se tornou pública entre alguns de seus amigos mais próximos e associados. ${ }^{39}$

Beza inicia seu texto dizendo que somente somos obrigados a obedecer incondicionalmente a Deus:

Príncipes, também, deveriam implicitamente ser obedecidos, se fossem sempre a voz dos comandos de Deus. Mas uma vez que o oposto ocorre muito frequentemente, uma exceção se impõe à obediência, quando seus comandos forem irreligiosos ou iníquos ${ }^{40}$.

A distinção que Beza realiza entre comandos irreligiosos e comandos iníquos ${ }^{41}$ é importante para nossos objetivos. Enquanto os comandos irreligiosos são aqueles que ferem a primeira tábua do decálogo de Moisés (os quatro deveres para com Deus), os comandos iníquos são aqueles que ferem a segunda tábua da lei (os seis deveres para com os homens). Essa distinção levará Beza a deixar de apelar apenas à suposta heresia ou idolatria para justificar qualquer

estritamente políticos (inclusive o argumento central do tratado), e não teológicos ou, muito menos, bíblicos.

39 FRANKLIN, Julian H. Introduction. IN: (ED.). Constitutionalism And Resistance In The Sixteenth Century: Three Treatises by Hotman, Beza, \& Mornay. New York: Pegasus, 1969. P. 30.

40 BEZA, Theodore. Right of the Magistrates. IN: FRANKLIN, Julian H. (ED.). Constitutionalism And Resistance In The Sixteenth Century: Three Treatises by Hotman, Beza, \& Mornay. New York: Pegasus, 1969. P. 101.

41 BEZA, Theodore. Right of the Magistrates. IN: FRANKLIN, Julian H. (ED.). Constitutionalism And Resistance In The Sixteenth Century: Three Treatises by Hotman, Beza, \& Mornay. New York: Pegasus, 1969. P. 101. 
resistência ao tirano. Em seu lugar, Beza invocará o dever de o magistrado promover o bem comum, cuja violação constitui-se no fundamento da resistência.

Beza afirma que não é lícito ao povo resistir ao governante legítimo ${ }^{42}$. O termo legítimo precisa ser melhor explicado: Beza não propõe nenhum critério material para se avaliar a legitimidade do poder, mas apenas um critério formal; legítimo é o governante com cujo poder o povo assentiu no passado. Esse assentimento pode ser direto (como no caso da aclamação) ou, o que é mais comum, através da fixação de um critério formal para se determinar quem assumiria o poder no futuro (por exemplo, uma linhagem de sucessão ao trono). O governante que não fosse legitimado direta ou formalmente seria ilegítimo, e o povo poderia resistir-lhe.

É possível que um governante (formalmente) legítimo se corrompa (materialmente, ou seja, ordenando aquilo que é errado), mas que ainda assim permaneça sendo formalmente legítimo, razão pela qual ele não pode ser desobedecido pelo povo em nenhuma circunstância:

a não ser no caso de um chamado especial de Deus ${ }^{43}$, do qual não tratarei aqui, ele não pode, por sua própria iniciativa, responder à força com a força, mas deve ou autoexilar-se ou suportar o jugo com confiança em Deus ${ }^{44}$.

42 BEZA, Theodore. Right of the Magistrates. IN: FRANKLIN, Julian H. (ED.). Constitutionalism And Resistance In The Sixteenth Century: Three Treatises by Hotman, Beza, \& Mornay. New York: Pegasus, 1969. P. 105.

43 A ideia de um "chamado especial de Deus" provavelmente refere-se àquilo que, na concepção de Weber, identifica-se com a emergência de um líder carismático. Essa ideia será tratada mais abaixo.

44 BEZA, Theodore. Right of the Magistrates. IN: FRANKLIN, Julian H. (ED.). Constitutionalism And Resistance In The Sixteenth Century: Three Treatises by Hotman, Beza, \& Mornay. New York: Pegasus, 1969. P. 108. 
Por outro lado, se o povo não pode apresentar resistência ao governante legítimo que viole os dez mandamentos, o magistrado menor pode e deve agir para resistir-lhe ${ }^{45}$, uma vez que as Escrituras não diferenciam entre o magistrado soberano e os magistrados menores, devendo "oferecer resistência à flagrante tirania e salvaguardar aqueles sob sua proteção," 46 até que um poder legítimo, superior ao governante tirânico, como os Estados Gerais, decida a questão.

Ainda que a argumentação de Beza seja política, como veremos mais à frente, ele acrescenta um exemplo bíblico acerca do direito de o magistrado menor resistir ao tirano: Davi resistiu a Saul quando esse enlouqueceu, e tal resistência foi aprovada por Deus.

Beza, por fim, acrescenta algo inusitado, que, de certa forma, já estava implícito no pensamento de Calvino: Ao longo do tempo, Deus levantou homens do povo (não magistrados) para fazerem justiça com suas próprias mãos e punirem os governantes irreligiosos ou iníquos. Ainda que o ato de um cidadão que tira a vida de um rei seja um crime e um pecado, de modo algum esse dado pode ser entendido fora da vontade soberana, da presciência e da predeterminação de Deus ${ }^{47}$ : A ideia da soberania absoluta de Deus, presente tanto no pensamento de Calvino quanto de Beza, impede que qualquer evento seja pensado como

45 BEZA, Theodore. Right of the Magistrates. IN: FRANKLIN, Julian H. (ED.). Constitutionalism And Resistance In The Sixteenth Century: Three Treatises by Hotman, Beza, \& Mornay. New York: Pegasus, 1969. P. 102.

46 BEZA, Theodore. Right of the Magistrates. IN: FRANKLIN, Julian H. (ED.). Constitutionalism And Resistance In The Sixteenth Century: Three Treatises by Hotman, Beza, \& Mornay. New York: Pegasus, 1969. P. 112.

47 BEZA, Theodore. Right of the Magistrates. IN: FRANKLIN, Julian H. (ED.). Constitutionalism And Resistance In The Sixteenth Century: Three Treatises by Hotman, Beza, \& Mornay. New York: Pegasus, 1969. P. 131. 
não ordenado por ele. Por essa razão, mesmo uma revolução ou um regicídio devem ser pensados como queridos por Deus, ainda que isso não exima, por exemplo, a culpa do conspirador ou homicida, e que não signifique também que o soberano era iníquo ou irreligioso (pois pode ter sido morto para se disciplinar o povo, substituindo-o por outro ainda mais iníquo ou irreligioso). Mas isso significa que também a revolução, a desobediência e o tiranicídio representam, de algum modo, a vontade de Deus. Como disse Calvino, Deus

por vezes (...) suscita algum de seus servos para vingar a tirania de quem injustamente os domina, livrando da calamidade um povo oprimido; por vezes, para o mesmo fim, suscita o furor dos homens que cogitam uma coisa e executam outra ${ }^{48}$.

\subsection{John Knox}

A proposta mais radical dentre os reformadores do século XVI que investigamos foi a de John Knox, discípulo de Calvino responsável por levar a reforma para a Escócia, fundando a Igreja Presbiteriana.

Em 1555 e 1556, Knox visitou a Escócia e, depois de pregar em várias igrejas, rapidamente o protestantismo de orientação calvinista espalhou-se por aquele país. Por causa disso, os bispos católicos escoceses intimaram-no a comparecer perante uma reunião de teólogos católicos. Tendo em vista o crescente sucesso de Knox, ela foi cancelada. Como Knox e seus apoiadores já se encontravam em Edimburgo para o evento, ele decidiu pregar nesta cidade no dia em que esse originalmente ocorreria, 15 de maio de 1556. A pedido dos nobres escoceses, Knox redige uma carta a Maria I da

48 CALVINO, João. A Instituição da religião cristã. São Paulo: UNESP, 2009. Tomo II (livros III e IV). P. 900. (item 30 do cap. XX do livro IV). 
Inglaterra, rainha católica que governou de 1553 a 1558, solicitando que fosse concedida a liberdade aos pastores protestantes para pregarem e que sua doutrina fosse ouvida por pessoas capazes de julgá-la. Depois que Knox partiu para Genebra, os bispos católicos reuniram-se novamente e julgaram-no à revelia, condenando-o. Knox então escreve mais duas cartas, a primeira destinada à nobreza, solicitando que anulasse a decisão dos bispos, e a segunda destinada ao povo, solicitando que não permitisse que os nobres se omitissem de seu dever de indicar pastores para o povo e de protege-los. Esses três documentos foram publicados em 1558, e receberam respectivamente o nome de Carta à rainha viúva, regente da Escócia; Apelação da sentença proferida pelos bispos e pelo clero dirigida à nobreza e aos estados gerais da Escócia e, finalmente, Carta dirigida à comunidade da Escócia ${ }^{49}$.

Nesses documentos, Knox irá defender três ideias realmente revolucionárias: 1) Knox afirmará que o poder eclesiástico e espiritual está submetido ao poder civil e temporal; 2) Knox defenderá a ideia de que o povo pode exigir dos magistrados civis que combatam a tirania;3) Knox afirmará que, caso os magistrados (no caso, a nobreza) não defendam o povo contra os tiranos, esse mesmo povo pode tomar em suas mãos a defesa contra a tirania.

$\mathrm{Na}$ Apelação da sentença proferida pelos bispos e pelo Clero, de 1558, dirigida aos nobres, Knox afirma que

É dever de todo homem, em sua vocação, mas predominantemente da nobreza, que a compartilha com seus reis, conter e reprimir a loucura e raiva cega [dos iníquos]. O que, se a nobreza não o fizer, nem se empenhar por fazê-lo (...) provoca a ira de Deus contra si mesma e contra todo o reino no qual abusa da autoridade que recebeu de Deus para manter as virtudes e reprimir o vício (...)

49 REED, Kevin (ed.) Editor`s Note. In: KNOX, John. Selected Writings: Public Epistles, treatises and Expositions to the year of 1559. Dallas: Presbyterian heritage, 1995. P. 438. 
Deus não isentará nem a nobreza nem o povo ${ }^{50}$.

Exatamente porque a ira de Deus recai sobre todo o reino (como, em Israel e em Judá, a ira de Deus recaía sobre todo o povo, e não apenas sobre os reis pecaminosos), o povo pode tomar a justiça em suas mãos e punir os magistrados que se isentarem do dever de punir os perversos (ainda que os perversos sejam outros magistrados): “A punição da idolatria não pertence apenas aos reis, mas a todo o povo" 51 , pois a salvação e a saúde do povo (salus publica) não compete apenas aos magistrados, mas também ao próprio povo ${ }^{52}$.

Essa posição será ainda mais radicalizada na Carta dirigida à comunidade da Escócia. Nela, Knox escreverá ao povo que

Apesar de eles serem apenas súditos, eles podem requerer legalmente de seus superiores (sejam reis, sejam senhores, governantes e autoridades) que forneçam pregadores habilitados (...). E se neste ponto os superiores forem negligentes, ou pretenderem manter tiranos em sua tirania, muito justamente o povo pode fornecer ele mesmo tais pregadores para si próprio" ${ }^{\prime 53}$. (546)

O povo tem o direito de exigir do rei que o defenda

50 KNOX, John. The Appellation from the Sentence Pronounced by the Bishops and Clergy: Addressed to the Nobility and Estates od Scotland. In:

Selected Writings: Public Epistles, treatises and Expositions to the year of 1559. Dallas: Presbyterian heritage, 1995. P. 507.

51 KNOX, John. The Appellation from the Sentence Pronounced by the Bishops and Clergy: Addressed to the Nobility and Estates od Scotland. In:

Selected Writings: Public Epistles, treatises and Expositions to the year of 1559. Dallas: Presbyterian heritage, 1995. P. 514

52 KNOX, John. Letter Addressed to the Commonalty of Scotland. In:

Selected Writings: Public Epistles, treatises and Expositions to the year of 1559. Dallas: Presbyterian heritage, 1995. P. 548.

53 KNOX, John. Letter Addressed to the Commonalty of Scotland. In:

Selected Writings: Public Epistles, treatises and Expositions to the year of 1559. Dallas: Presbyterian heritage, 1995. P. 546. 
contra toda injustiça, iniquidade e irreligião. Se o rei não o fizer, o povo tem o direito de exigir da nobreza que o defenda contra o rei. Se a nobreza não o fizer, o povo tem o direito de tomar a espada em suas próprias mãos e fazê-lo porque, se não o fizer, a ira de Deus recairá não apenas sobre o tirano, o iníquo, o defensor da irreligião, o rei ou os nobres, mas sobre todo o reino e, portanto, sobre o próprio povo. O povo é então responsável pelo seu próprio bem-estar.

\section{Um novo conceito de soberania}

Há uma grande distância entre Lutero e Knox, entre o resignar-se diante da tirania com obediência absoluta ao poder formalmente instituído e o avaliar o poder e decidir obedecê-lo ou opor-se a ele. Como é possível que em tão pouco tempo, não mais do que trinta e cinco anos, os reformadores tenham mudado de maneira tão radical o seu entendimento? A resposta para esta questão está na mudança operada no próprio conceito de soberania, de seus fundamentos e origem e de seus limites.

Para verificarmos como isso ocorreu, além de investigarmos a própria mudança do conceito (da soberania do rei à soberania popular), precisamos investigar o problema da relação entre o poder espiritual e o poder temporal e o problema do papel que se atribuiu de forma crescente ao poder fundamentador da razão. 


\subsection{Da separação entre o reino temporal e o reino espiritual à submissão do reino espiritual ao temporal}

Uma das doutrinas centrais da Reforma Protestante é a doutrina luterana do sacerdócio universal dos fiéis, que, apesar de se apresentar em sua forma definitiva apenas no Cativeiro Babilônico da Igreja, de 1521, começa a se apresentar e a se estruturar já no Apelo à Nobreza Alemã acerca da situação cristã, publicado poucos meses antes de Cativeiro. Neste texto, Lutero afirmou que "todos nós somos consagrados sacerdotes por meio do batismo" 54 (Apelo, 12), e que o ministro religioso difere-se do fiel apenas pelo exercício (temporário) de um cargo $^{55}$. Essa doutrina tem uma consequência importante para o modo como se concebe a relação entre Direito e Religião: a diferença entre os ministros dessas duas esferas é apenas do exercício do poder, e não de natureza.

O sacerdócio universal dos fiéis está na base da doutrina dos dois reinos de Lutero, pois "todos os cristãos pertencem ao estamento espiritual, e não há nenhuma diferença entre eles a não ser de ofício" 56 , e "não há nenhuma diferença básica verdadeira entre leigos e padres, príncipes e bispos, entre religiosos e seculares, a não ser com relação ao ofício e ao trabalho" 57 .

54 LUTHER, Martin. To the Christian Nobility of the German Nation. In: Three Treatises. Philadelphia: Fortress, 1970. P. 12.

55 LUTHER, Martin. To the Christian Nobility of the German Nation. In: Three Treatises. Philadelphia: Fortress, 1970. P. 14.

56 LUTHER, Martin. To the Christian Nobility of the German Nation. In: Three Treatises. Philadelphia: Fortress, 1970. P. 12.

57 LUTHER, Martin. To the Christian Nobility of the German Nation. In: Three Treatises. Philadelphia: Fortress, 1970. P. 14. 
Se a diferença entre os homens não é de natureza, mas de exercício de cargos, se a diferença entre bispos e príncipes não é de natureza, mas de funções distintas, então essa distinção de funções dá origem a dois reinos, que se sobrepõem espacialmente mas que se distinguem por suas funções: o reino espiritual e o reino temporal. Se os dois reinos possuem funções distintas, apesar de se superporem espacialmente, é preciso separá-los quanto às funções, aos cargos e ao poder de cada um deles. Por isso, "nenhum assunto temporal deve ser atribuído a Roma, mas todos esses casos [da relação dos súditos de um Estado com o poder civil] devem ser deixados à autoridade temporal, como os próprios romanistas prescrevem em sua lei canônica, que eles próprios não observam" ${ }^{58}$. A consequência disso é a não submissão de um reino (espiritual e temporal) ao outro, como afirma o próprio Lutero: “Ao papa não deve ser concedida autoridade sobre o Imperador, a não ser para ungí-lo e coroá-lo diante do altar, mas apenas como um bispo coroa um rei" 59 .

Essa posição clássica de Lutero é muito diferente da posição dos autores calvinistas, em especial de John Knox, para quem todo poder ${ }^{60}$ se submete, em última instância, ao poder civil. Esse argumento é central em seus textos, já que ele pretende que os magistrados civis anulem a decisão dos Bispos Católicos que o condenara. Como ele afirma, "é legítimo que os profetas de Deus apelem de uma sentença e julgamento da igreja visível ao conhecimento do magistrado

58 LUTHER, Martin. To the Christian Nobility of the German Nation. In: Three Treatises. Philadelphia: Fortress, 1970. P. 48.

59 LUTHER, Martin. To the Christian Nobility of the German Nation. In: Three Treatises. Philadelphia: Fortress, 1970. P. 53.

60 Ainda que Deus não esteja submetido ao poder civil, o poder exercido pela Igreja visível, enquanto instituição, é exercido por homens, estando sujeita, portanto, às falhas humanas, e por isso, ainda que seja um poder espiritual, também está sujeita ao controle pelo poder civil. 
temporal, a quem Deus ordenou que ouvisse a causa deles e os defendesse da tirania" ${ }^{61}$. Knox apresenta dois exemplos disso na Bíblia: o profeta Jeremias recorre aos príncipes de Israel da condenação (de natureza religiosa) que os sacerdotes lhe haviam imposto ${ }^{62}$, e é por eles absolvido. Do mesmo modo, o apóstolo Paulo recorre a César da condenação que os sacerdotes de Israel lhe impuseram ${ }^{63}$. Seguindo o ensinamento de Crisóstomo, Knox afirma que Deus não isentou "qualquer pessoa da obediência e sujeição ao poder civil" 64, nem mesmo os ministros do poder espiritual, razão pela qual não há independência entre os dois reinos, mas submissão do reino espiritual, no que concerne à igreja visível, ao reino temporal, pois

Se Aarão e seus filhos [detentores do poder espiritual] se submetiam a Moisés [detentor do poder temporal], de tal forma que não faziam nada a não ser o que ele ordenasse, quem ousaria ser tão ousado e afirmar que o poder civil não tem nenhuma competência em matéria de religião ${ }^{65}$ ?

61 KNOX, John. The Appellation from the Sentence Pronounced by the Bishops and Clergy: Addressed to the Nobility and Estates od Scotland. In:

Selected Writings: Public Epistles, treatises and Expositions to the year of 1559. Dallas: Presbyterian heritage, 1995. P. 478.

62 KNOX, John. The Appellation from the Sentence Pronounced by the Bishops and Clergy: Addressed to the Nobility and Estates od Scotland. In:

Selected Writings: Public Epistles, treatises and Expositions to the year of 1559. Dallas: Presbyterian heritage, 1995. P. 479.

63 KNOX, John. The Appellation from the Sentence Pronounced by the Bishops and Clergy: Addressed to the Nobility and Estates od Scotland. In:

Selected Writings: Public Epistles, treatises and Expositions to the year of 1559. Dallas: Presbyterian heritage, 1995. P. 483.

64 KNOX, John. The Appellation from the Sentence Pronounced by the Bishops and Clergy: Addressed to the Nobility and Estates od Scotland. In:

Selected Writings: Public Epistles, treatises and Expositions to the year of 1559. Dallas: Presbyterian heritage, 1995. P. 522

65 KNOX, John. The Appellation from the Sentence Pronounced by the Bishops and Clergy: Addressed to the Nobility and Estates od Scotland. In:

Selected Writings: Public Epistles, treatises and Expositions to the year of 
Essa nova maneira de se conceber a relação entre poder temporal e poder espiritual será essencial para os rumos que a secularização, entendida como "diferenciação e especialização progressiva", mas também como "princípio de legitimação" ${ }^{\prime \prime}$, tomou no mundo ocidental contemporâneo.

\subsection{A razão como fundamento do direito}

Todos os reformadores apontarão a existência de limites racionais ao conteúdo dos mandados e das leis exaradas pelos governantes. Esses limites foram estabelecidos por Deus, e podem ser conhecidos na natureza. Já Lutero, por exemplo, afirmava que "o direito escrito deveria ficar sujeito à razão, pois surgiu dela, que é a fonte de todo o direito. Não deveria fazer a fonte depender dos arroiozinhos ${ }^{67} \mathrm{e}$ aprisionar a razão com letras" 68 .

A Confissão de Magdeburg fornece três argumentos que indicam o dever de os mandados do governante serem fundamentados na razão. Em primeiro lugar, o magistrado é ordenado por Deus e, por isso, quando não segue sua lei, que funciona como um limite e como fonte de legitimação material, não é mais uma ordenança de Deus, mas do demônio ${ }^{69}$. O segundo argumento afirma que Cristo separou o reino temporal e o reino espiritual, mas submeteu ambos ao poder e pré-desígnio de Deus. Quando o magistrado nega isso, afastando-se do que Deus deseja para seu povo, está

1559. Dallas: Presbyterian heritage, 1995. P. 495.

66 MARRAMAO, Giacomo. Poder e secularização: As categorias do tempo. São Paulo: Universidade Estadual Paulista, 1995. P. 31

67 A tradição e os costumes.

68 LUTERO, Martinho. Da autoridade secular: Até que ponto se lhe deve obediência. In: BONI, Luis Alberto de (org.). Escritos seletos de Martinho Lutero, Tomás Müntzer e João Calvino . Petrópolis: Vozes, 2000. P. 123.

69 AMSDORFF, Nicholas von et alii. The Magdeburg Confession. Trad. Mathew Colvin. North Charleston: Create Space, 2012. P. 59. 
sujeito à vingança, realizada por meio de mãos humanas escolhidas por Deus para esse fim ${ }^{70}$. O terceiro argumento diz que em Gênesis, capítulo 9, aquele que derramar sangue humano, terá seu sangue derramado ${ }^{71}$. Crer que Deus não nos autoriza a nos rebelarmos contra o mau e a tirania seria crer que Deus autoriza o próprio mau, pois Deus sempre puniu os maus governantes, muitas vezes diretamente, muitas vezes por mãos de outros homens.

Calvino também acredita que existam limites materiais ao poder do magistrado, que se revelam pela razão ${ }^{72}$. Essa ideia influenciará os calvinistas que lhe sucederam, como Beza e Knox. Para Beza, quando os súditos têm sua consciência perturbada por não compreenderem a razão de ser de uma norma aparentemente injusta, eles podem (e devem, diz Beza) exigir que o soberano lhes apresente a razão (ou a "equidade", para usar sua terminologia) da obediência $^{73}$. Knox também afirma que a razão, e não a vontade apenas, é o fundamento da obediência, e portanto a falta de razão pode motivar e fundamentar a desobediência dos súditos ${ }^{74}$.

70 AMSDORFF, Nicholas von et alii. The Magdeburg Confession. Trad. Mathew Colvin. North Charleston: Create Space, 2012. P. 65.

71 Note que essa lei foi estabelecida antes da lei mosaica, que era uma lei que se aplicaria apenas ao povo que faz um pacto com Deus, ou seja, aos Judeus. A lei que exige que o sangue derramado seja aplacado com o derramamento do sangue do criminoso, que integra o que se chama de Lei de Noé, é, portanto, uma lei que vale universalmente.

72 CALVINO, João. A Instituição da religião cristã. São Paulo: UNESP, 2009. Tomo II (livros III e IV). P. 897. (item 25 do cap. XX do livro IV).

73 BEZA, Theodore. Right of the Magistrates. IN: FRANKLIN, Julian H. (ED.). Constitutionalism And Resistance In The Sixteenth Century: Three Treatises by Hotman, Beza, \& Mornay. New York: Pegasus, 1969. P. 101.

74 KNOX, John. The Appellation from the Sentence Pronounced by the Bishops and Clergy: Addressed to the Nobility and Estates od Scotland. In:

Selected Writings: Public Epistles, treatises and Expositions to the year of 1559. Dallas: Presbyterian heritage, 1995. P. 505. 
A visão positiva que Calvino e os calvinistas têm acerca do Estado, em contraposição à visão clássica luterana, para quem o Estado é um mal necessário, implica uma nova concepção acerca do que é o poder civil. Este não é, para Calvino e seus seguidores (e ainda mais para estes), apenas a violência ${ }^{75}$, pois a razão pode revelar o que é o certo a se fazer. O poder, então, passa a ser conformado pela razão, e passa a ser um mecanismo da construção do reino de Deus na Terra. Por isso, entre os reformadores há a convicção de que a autoridade não se sustenta apenas na vontade do soberano. O soberano incapaz de apresentar razões para suas ordens perde o substrato do fundamento de seu poder, pois sua vontade se identifica com caprichos e, segundo Knox, deve ser desobedecida.

\subsection{Soberania popular, contrato social e (des) obediência}

O texto de Beza revela que, para além de argumentos bíblico-teológicos, a alteração da orientação dos reformadores acerca da autoridade civil não pode se ser compreendida sem analisarmos a alteração da teoria política operada pela filosofia moderna.

O ponto de partida de Beza é que o poder do governante não é na sua origem natural, mas fruto do consentimento dado pelos súditos, e, portanto, de um contrato. Portanto, muito mais do que teológico, ou mesmo moral, seu poder possui uma natureza política:

Começo apontando que os povos não se originam nos governantes; que os povos, tenham eles escolhidos serem governados por um único príncipe ou por um grupo de notáveis eleitos, são mais

75 Se o poder civil fosse apenas a violência, não seria possível se opor a ele. 
antigos que os governantes; e, seguindo isso, que as pessoas não são criadas para os governantes, mas ao contrário os governantes (são criados) para as pessoas ${ }^{76}$.

Podemos falar da existência de um protocontratualismo em Beza: como a origem do poder do rei é o consentimento dos súditos, é um contrato (entendido não como uma hipótese regulativa, como será interpretado pelos contratualistas do século XVII e XVIII, mas como um evento real, histórico) que explica a distribuição do poder em uma dada sociedade. Esse contrato, no entanto, é um contrato sem qualquer reserva, e portanto uma vez transferido o poder do povo ao soberano, não mais é possível o exercício de qualquer controle por parte do povo sobre seu poder. Se esse poder se corrompe, o povo não pode a princípio invocar uma cláusula rebus sic stantibus e pretender que o poder do rei não seja mais legítimo. Pensar o contrário seria autorizar que o povo abandonasse o contrato e retornasse à situação anterior, caótica e pouco civilizada, onde a maldade particular imperava, o que seria ainda pior do que suportar o rei injusto, mas formalmente legítimo:

Um governante que foi reconhecido pelo seu povo pode abusar de seu domínio e ainda reter sua autoridade sobre os súditos privados, porque a obrigação de obedecê-lo foi publicamente contratada pelo consentimento comum e não pode ser desfeita ou anulada pela vontade dos particulares. Se não fosse assim, problemas infinitos ainda piores que a própria tirania ocorreriam, e milhares de tiranos surgiriam sob o pretexto de se extinguir $\mathrm{um}^{77}$.

Há no entanto duas exceções para a indissolubilidade do contrato que dá origem ao Estado: A primeira trata-se

76 BEZA, Theodore. Right of the Magistrates. IN: FRANKLIN, Julian H. (ED.). Constitutionalism And Resistance In The Sixteenth Century: Three Treatises by Hotman, Beza, \& Mornay. New York: Pegasus, 1969. P. 104.

77 BEZA, Theodore. Right of the Magistrates. IN: FRANKLIN, Julian H. (ED.). Constitutionalism And Resistance In The Sixteenth Century: Three Treatises by Hotman, Beza, \& Mornay. New York: Pegasus, 1969. P. 109. 
do caso do governante usurpador, que toma o governo ilegitimamente, pois "aqueles que, por força e fraude, usurparam o poder que não lhes pertence por direito não são reis legítimos"78. Como o povo não possui nenhum vínculo contratual com o usurpador, ele não lhe deve obediência. Nesse caso,

O cidadão privado deve apelar ao magistrado legítimo de tal forma que o inimigo público possa ser repelido pela autoridade pública (...). Mas se os magistrados, por conivência ou qualquer outra causa, falharem em seu dever, então cada cidadão privado pode exercer sua força para defender as instituições legítimas de seu país ${ }^{79}$.

Em segundo lugar, nem todos os comandos queridos pelo soberano (formalmente) legítimo são de fato autorizados. Segundo Beza, a equidade, ou seja, o justo natural, é um limite para o conteúdo dos comandos do soberano, porque seria absurdo pressupor-se que o povo daria o consentimento para fazer de alguém governante se isso representasse a supressão de sua liberdade e de seus direitos ${ }^{80}$. Deve ser desacreditada, portanto, a ideia corrente de que "a vontade do rei seja sempre suficiente para os súditos, uma vez que isso não se funda nem na razão, nem no uso estabelecido das monarquias $^{\prime 81}$. Se a vontade é o que explica a transferência

78 BEZA, Theodore. Right of the Magistrates. IN: FRANKLIN, Julian H. (ED.). Constitutionalism And Resistance In The Sixteenth Century: Three Treatises by Hotman, Beza, \& Mornay. New York: Pegasus, 1969. P. 105.

79 BEZA, Theodore. Right of the Magistrates. IN: FRANKLIN, Julian H. (ED.). Constitutionalism And Resistance In The Sixteenth Century: Three Treatises by Hotman, Beza, \& Mornay. New York: Pegasus, 1969. P. 107.

80 BEZA, Theodore. Right of the Magistrates. IN: FRANKLIN, Julian H. (ED.). Constitutionalism And Resistance In The Sixteenth Century: Three Treatises by Hotman, Beza, \& Mornay. New York: Pegasus, 1969. P. 109.

81 BEZA, Theodore. Right of the Magistrates. IN: FRANKLIN, Julian H. (ED.). Constitutionalism And Resistance In The Sixteenth Century: Three Treatises by Hotman, Beza, \& Mornay. New York: Pegasus, 1969. P. 132. 
fática do poder do povo para o governante, é a razão que autoriza o povo legitimamente a transferir, pela vontade, o poder ao governante. E se o povo não pode lançar mão de armas para destituir o mau governante legitimamente investido de seu poder, ele pode recorrer aos magistrados menores para que esses o livrem do tirano. $\mathrm{E}$

Apesar de os magistrados estarem sob [o poder de] o soberano, no sentido de receberem ordens dele, serem instalados nos cargos e aprovados por ele, eles se submetem não propriamente ao soberano, mas à soberania. Eis porque, quando o magistrado soberano morre, eles no entanto permanecem no cargo, assim como a soberania em si mesma permanece intacta. (...) é portanto evidente que há uma obrigação mútua entre os reis e os oficiais do reino, que o governo do reino não está exclusivamente nas mãos do rei, mas apenas a .parcela soberana do poder está em suas mãos, que cada oficial tem uma parte do poder ligada ao seu posto e grau, e que há condições (para o exercício do poder) bem definidas tanto para o soberano quanto para os oficiais ${ }^{82}$.

Esse argumento também é apresentado por Knox, para quem a função dos magistrados não é servir ao rei, mas servilo (como um meio) para (o fim de se alcançar) a glória de Deus e a preservação da comunidade. Dizer que a função dos magistrados é servir ao rei para a glória de Deus significa que existem limites revelados pela razão acerca do conteúdo de seu poder, e dizer que sua função é preservar a comunidade significa que existem limites formais ao exercício do poder pelo magistrado que se realizam na vontade do povo que o torna magistrado ${ }^{83}$. Por isso, afirmar que Deus sempre ordena

82 BEZA, Theodore. Right of the Magistrates. IN: FRANKLIN, Julian H. (ED.). Constitutionalism And Resistance In The Sixteenth Century: Three Treatises by Hotman, Beza, \& Mornay. New York: Pegasus, 1969. P. 111.

83 KNOX, John. The Appellation from the Sentence Pronounced by the Bishops and Clergy: Addressed to the Nobility and Estates od Scotland. In:

Selected Writings: Public Epistles, treatises and Expositions to the year of 1559. Dallas: Presbyterian heritage, 1995. P. 504. 
obedecermos ao magistrado, em especial ao soberano, seria uma blasfêmia equivalente a dizer que Deus ordena coisas iníquas $^{84}$.

Beza entende que o contrato que transfere o poder do povo para o soberano se realiza por meio dos estados gerais, e que

em todos os acordos baseados apenas no consentimento das partes contratantes, a obrigação pode ser rompida por aqueles que possuem uma razão suficiente - do que se segue que aqueles que possuem o direito de fazer um rei, também possuem o direito de depô-lo, [... e que esse direito torna-se aplicável quando] existir alguma ocasião [...] em que a obrigação anula-se a si mesma quando houve uma flagrante violação das condições essenciais em função da qual a obrigação foi contratada ${ }^{85}$.

Se o povo não possui o direito de invocar a cláusula rebus sic stantibus para cassar o poder do tirano, os estados gerais, no entanto, podem fazê-lo. Uma prova disso é que mesmo o papa está submetido ao concílio, que pode depôlo, como fez o concílio de Constança em 1417, para por fim ao Grande Cisma ${ }^{86}$.

O problema do contrato, por sua vez, leva ao problema da submissão do governante à lei. Beza observa inicialmente que nunca houve um rei na Bíblia que não fosse corrupto ou tirânico ${ }^{87}$, e que mesmo o grande rei Davi providenciou

84 KNOX, John. The Appellation from the Sentence Pronounced by the Bishops and Clergy: Addressed to the Nobility and Estates od Scotland. In:

Selected Writings: Public Epistles, treatises and Expositions to the year of 1559. Dallas: Presbyterian heritage, 1995. P. 505.

85 BEZA, Theodore. Right of the Magistrates. IN: FRANKLIN, Julian H. (ED.). Constitutionalism And Resistance In The Sixteenth Century: Three Treatises by Hotman, Beza, \& Mornay. New York: Pegasus, 1969. P. 124.

86 BEZA, Theodore. Right of the Magistrates. IN: FRANKLIN, Julian H. (ED.). Constitutionalism And Resistance In The Sixteenth Century: Three Treatises by Hotman, Beza, \& Mornay. New York: Pegasus, 1969. P. 129.

87 BEZA, Theodore. Right of the Magistrates. IN: FRANKLIN, Julian H. (ED.). 
um plano para tirar a vida de seu fiel servo Urias para que Davi pudesse se unir à viúva, Bate-Seba. Os reis são assim provavelmente porque neles a vontade suplanta a razão ${ }^{88}$. A vontade deveria ser sempre a vontade do povo que o constitui, revela-o a razão, mas o rei acaba suplantando essa vontade pela sua própria vontade. A única forma de se evitar que o rei se corrompa pela sua vontade é submetendo-o à lei. Beza afirma, portanto, o primado da lei no governo nãotirânico:

Dizer que o soberano não esteja submetido à lei é certamente uma máxima falsa de aduladores detestáveis, não de um súdito leal a seu príncipe. Ao contrário, não há uma única lei a que o governante não esteja ligado na condição de seu governo, uma vez que ele jurou ser o protetor e o preservador de todas (as leis) ${ }^{89}$.

Essa é, portanto, a primeira estratégia para se combater a tirania: compreender o poder do rei como originado por um contrato que o obriga a submeter-se à própria lei. A segunda estratégia para controlar o poder é dividi-lo entre o magistrado soberano e os magistrados menores. Essa doutrina apareceu pela primeira vez na Confissão de Magdeburg. Essa divisão do poder é defendida na Confissão tanto por um argumento de direito privado (o contrato de vassalagem entre o rei e os nobres, que divide o poder daquele com esses) quanto por um argumento de direito público (a necessidade de se compreender o império como uma federação centrípeta, formada pela união dos diversos domínios dos magistrados menores). O poder, portanto,

Constitutionalism And Resistance In The Sixteenth Century: Three Treatises by Hotman, Beza, \& Mornay. New York: Pegasus, 1969. P. 116.

88 BEZA, Theodore. Right of the Magistrates. IN: FRANKLIN, Julian H. (ED.). Constitutionalism And Resistance In The Sixteenth Century: Three Treatises by Hotman, Beza, \& Mornay. New York: Pegasus, 1969. P. 117.

89 BEZA, Theodore. Right of the Magistrates. IN: FRANKLIN, Julian H. (ED.). Constitutionalism And Resistance In The Sixteenth Century: Three Treatises by Hotman, Beza, \& Mornay. New York: Pegasus, 1969. P. 113. 
é dividido e partilhado entre o soberano e os magistrados menores, e é isso que autoriza sua resistência à tirania.

Essa ideia já era compartilhada, em um certo sentido, por Calvino, para quem, se a aristocracia seria idealmente a melhor forma de governo, e a monarquia seria a pior de suas formas, na prática é a democracia a melhor forma de governo, porque implica a maior divisão do poder pelo maior número de pessoas, afastando-se assim a influência nefasta da vontade individual sobre o poder:

é verdade que um rei, ou outra pessoa investida de autoridade única, facilmente caia na tirania; é fácil também que os nobres se conluiam para criar um governo injusto; mais frequente ainda são as sedições, quando o povo assume o poder. Comparando [as] três formas de governos, será preferível que o poder esteja nas mãos daqueles que sabem governar mantendo a liberdade do povo, visto que raramente se constata, sendo quase um milagre, que os reis consigam controlar a sua vontade sem jamais se afastarem da justiça e da retidão. (...) Por isso, na falta de homens aptos, e também por causa do pecado, a forma de autoridade mais segura costuma ser a de um governo constituído por pessoas que se ajudam mutuamente e se admoestam no exercício do seu dever; e se alguém se exalta mais do que é justo, muitos são os censores e mestres que coibirão esse desregramento ${ }^{90}$.

Isso significa que a mudança na atitude diante da autoridade civil corresponde a uma alteração do próprio conceito de soberania, entendido antes como um atributo pessoal do rei e, já em meados do século XVI, como soberania popular. Não é coincidência, portanto, que possamos estabelecer uma gradação que vai de Lutero a Knox, passando por Calvino e Beza. Quanto mais popular era o processo de Reforma, mais a compreensão dos limites da autoridade civil se aproximavam da soberania popular. E enquanto a Reforma, na Alemanha, foi um movimento de nobres, e não

90 CALVINO, João. A Instituição da religião cristã. São Paulo: UNESP, 2009. Tomo II (livros III e IV). P. 881. (item 8 do cap. XX do livro IV). 
de quaisquer nobres, mas dos nobres da mais alta estirpe, os Príncipes Eleitores, a Reforma na Escócia foi empreendida pelo povo ${ }^{91}$. Daí a necessidade de Knox, diferentemente do que ocorre com Lutero, que escreve sempre aos nobres, de escrever ao povo. E daí sua reivindicação de que o povo, origem, em última instância, da soberania, pudesse tomar em suas próprias mãos o combate à tirania.

\section{Referências}

AMSDORFF, Nicholas von et alii. The Magdeburg Confession. Trad. Mathew Colvin. North Charleston: Create Space, 2012. BARTH, Karl. The epistle to the Romans. Oxford: Oxford University, 1968.

BEZA, Theodore. Right of the Magistrates. IN: FRANKLIN, Julian H. (ED.). Constitutionalism And Resistance In The Sixteenth Century: Three Treatises by Hotman, Beza, \& Mornay. New York: Pegasus, 1969.

CALVIN, John. The Commentaries of M. John Calvin upon the Actes of the Apostles. In: Calvin's Commentaries. Grand Rapids: Baker, 2005. Vol. XVIII [parte II].

CALVINO, João. A Instituição da religião cristã. São Paulo: UNESP, 2009. Tomo II (livros III e IV).

FRANKLIN, Julian H. Introduction. IN: (ED.).

Constitutionalism And Resistance In The Sixteenth Century: Three Treatises by Hotman, Beza, \& Mornay. New York: Pegasus, 1969.

GRANT, George. Historical Postscript. In: AMSDORFF, Nicholas von. The Magdeburg Confession. Trad. Matthew Colvin. North Charleston: Create Space, 2012.

GRANT, George. Historical Setting. In: AMSDORFF, Nicho-

91 SKINNER, Quentin. As fundações do pensamento político moderno. São Paulo: Companhia das Letras, 1996. p. 485. 
las von. The Magdeburg Confession. Trad. Matthew Colvin. North Charleston: Create Space, 2012.

KNOX, John. Letter Addressed to the Commonalty of Scotland. In: Selected Writings: Public Epistles, treatises and Expositions to the year of 1559. Dallas: Presbyterian heritage, 1995.

KNOX, John. The Appellation from the Sentence Pronounced by the Bishops and Clergy: Addressed to the Nobility and Estates od Scotland. In: Selected Writings: Public Epistles, treatises and Expositions to the year of 1559. Dallas: Presbyterian heritage, 1995.

LINDBERG, Carter. História da Reforma. Rio de Janeiro: Thomas Nelson, 2017

LUCAS (São). Atos dos Apóstolos. In BÍBLIA SAGRADA. Tradução Ecumênica da Bíblia. São Paulo: Loyola, 1994.

LUTERO, Martinho. Contra as hordas salteadoras e assassinas dos camponeses. In: BONI, Luis Alberto de (org.). Escritos seletos de Martinho Lutero, Tomás Müntzer e João Calvino. Petrópolis: Vozes, 2000.

LUTERO, Martinho. Da autoridade secular: Até que ponto se lhe deve obediência. In: BONI, Luis Alberto de (org.). Escritos seletos de Martinho Lutero, Tomás Müntzer e João Calvino. Petrópolis: Vozes, 2000.

LUTHER, Martin. To the Christian Nobility of the German Nation. In: Three Treatises. Philadelphia: Fortress, 1970.

MARRAMAO, Giacomo. Poder e secularização: As categorias do tempo. São Paulo: Universidade Estadual Paulista, 1995. PAULO (Apóstolo). Epístola aos Romanos. In BÍBLIA SAGRADA. Tradução Ecumênica da Bíblia. São Paulo: Loyola, 1994. 
PEDRO (Apóstolo). Primeira Epístola de Pedro. In BÍBLIA SAGRADA. Tradução Ecumênica da Bíblia. São Paulo: Loyola, 1994.

REED, Kevin (ed.) Editor`s Note. In: KNOX, John. Selected Writings: Public Epistles, treatises and Expositions to the year of 1559. Dallas: Presbyterian heritage, 1995.

SKINNER, Quentin. As fundações do pensamento político moderno. São Paulo: Companhia das Letras, 1996. p. 485.

Recebido em 06/12/2018

Aprovado em 09/05/2019

Marcelo Campos Galuppo

E-mail:marcelogaluppo@uol.com.br 